\section{The Need for} Politics to Regulate the Technological Revolution

\author{
Roberto Palea
}

Klaus Schwab

The Fourth Industrial Revolution

New York, Crown Publishing Group, 2016

Klaus Schwab is the founder and Executive Chairman of the World Economic Forum, an organisation for public and private cooperation based in Geneva, Switzerland. His role, combined with his rich experience as an academic, entrepreneur and expert in political affairs, has offered him a privileged view angel from which to grasp the rapid technological advances that have been taking place in recent years and evaluate their possible consequences for the economy, society and politics all over the world.

Schwab is convinced that the rapid (and in certain cases even instant) technological advances resulting from the digital revolution, "big data" and the applications of Artificial Intelligence (A.I.) will mark the beginning of a radical transformation in the way we live, work and communicate today, which he does not hesitate to define as the results of a "fourth industrial revolution". In fact, according to Schwab, the first industrial revolution began in the second half of the 18th century with the invention of the steam engine followed by the internal combustion engine, both based on the combustion of fossil resources.

The second industrial revolution was marked by the advent of electricity and the introduction of the assembly line into industrial production.

The third industrial revolution began in the 1960s and is often referred to as "digital or IT revolution", as it is based on the development of semiconductors, "mainframe computers", personal computers and the Internet network.

The current development phase of technology is a consequence of the digital revolution and is characterised by: increasingly widespread use of the Internet, which is being more and more frequently accessed by increasingly smaller, more powerful and less expensive mobile devices; the use of Artificial Intelligence (A.I.) and its interaction with human intelligence; and the introduction of robots that are able to operate independently and to self-correct.

According to Schwab, there are three points that lead us to argue that we are facing a fourth and distinct industrial revolution: first, the exponential rate at which new technology is developing; then, the scope and intensity of what it entails (even combining different technologies), which not only concerns "what to do" and "how to do it", but also "who we are", even questioning the meaning of "human being"; and, finally, the impact on systems, namely on the countries, different sectors and global society in general.

I have recently noticed that Schwab's classification is now in the public domain and 
is being used not only by students but also by international governments and institutions, which currently refer to "Industry 4.0 " and "fourth industrial revolution" in the field of innovation and technological change underway.

Schwab describes, exhaustively, the profound and systemic changes that we can expect by combining the physical, digital and biological spheres, and their profound impact on all disciplines and economic as well as productive sectors.

He also highlights the enormous risks that are in contrast with great opportunities for change, which must be managed to ensure the common good.

One expected risk, which I am particularly concerned about, is the impact on the reduction in the number of people employed in economic sectors.

Schwab rightly criticises the position of the "techno-optimists" who, while acknowledging the consequences of new technologies on employment, believe that, in the end, increased productivity and wellbeing have always been achieved, and this has in turn increased the demand for goods and services that have made it necessary to require new jobs to satisfy them.

According to them, since human needs and desires are unlimited, the process of satisfying them should also be unlimited.

In short, we will never run out of work however work will be transformed.

Indeed, empirical evidence shows the opposite, namely that in a few decades the creation of a number of technological innovations will replace human labour in many areas and in professional activities.

In my view, in any case, the impact of technological innovations on human labour necessarily requires differentiated assessments in space and time. If we only look at Western societies with longerstanding industrialisation, human labour will be heavily penalised, at least in the short run.
Therefore, in anticipation of future benefits (which must be shared by all), society will have to bear the immediate costs of changing the industrial paradigm.

Hence, the issue of basic income should be quickly addressed if only starting with the generalised non-employment income.

If we broaden our outlook on the whole world, it is very likely that without global control and management of the events, any employment benefits will be shifted mainly to those industrialising countries that are making significant investments in education and training of human capital, such as China and India. It is as likely that, again without global management of the phenomena, in the West, economic crises, speculative bubbles breaks, trends towards income pulverisation and wealth concentration in the hands of few people will be recurrent and similar to what has already been experienced in the last decade.

All this is made worse by the aggravation of the planet's environmental conditions, ongoing wars, the risks of new and even more terrible international conflicts, as well as continuing, probably increasing, migration flows.

Schwab realises that new technology and

A.I. must be forces that help resolve, rather than exacerbate, the problems affecting humanity and our planet. However, he is unable to go beyond suggesting "developing forms of collaboration between economic and political forces capable of overcoming geographical boundaries and sectoral and disciplinary delimitations".

In fact, a lot more is required: a world democratic government and, for the immediate future, the strengthening of existing world institutions, first of all the UN and the WTO, which will have more autonomous government powers, more resources, and more democratic legitimacy. In addition, we cannot forget all those excluded from all or, at least, many of the 
industrial revolutions classified (as four) by Schwab, namely the one billion people suffering from hunger; those who live with income below poverty levels; $17 \%$ of Earth's inhabitants (1.3 billion people) who do not have access to electricity and half of the world's population who do not have Internet access.

There are two remarkable documents which are the basis for an effective programme on what to do in the world not only regarding the availability of new technologies for the benefit of mankind and the planet, but also regarding the cure of the evils which plague it: the "Agenda 2030 for Sustainable Development of the United Nations" and the "Paris Climate Agreement", whose contents perfectly complement each other.

Their validity and effectiveness were solemnly reiterated in the last G20 meetings in China in 2016 and recently (July 2017) in Hamburg, where only the "bizarre" President Trump withdrew.

The problem of what to do to get the G20 leaders to act on their international pledges remains unsolved. 